\title{
Stoffeinteilung
}

I. Band, erste Hälfte:

\section{Einfïhrung in das Gesamtwerk}

1. Kapitel: Die Grundlagen der organischen Chemie

\section{Systematische organische Chemie}

2. Kapitel: Die Kohlenwasserstoffe

3. Kapitel: Die organischen Halogenverbindungen

4. Kapitel: Dio organischen Sauerstoffverbindungen (Oxyverbindungen, Oxoverbindungen, Carbonsäuren, Kohlensäurederivate)

5. Kapitel: Verbindungen mit mehreren Sauerstoff-Funktionen im Molekül

I. Band, zweite Hälfte:

6. Kapitel: Die organischen Stickstoffrerbindungen

7. Kapitel: Die organischen Schwefelverbindungen

8. Kapitel: Die organischen Verbindungen der übrigen Nichtmetalle

9. Kapitel: Die metallorganischen Verbindungen

10. Kapitel: Verbindungen mit anomalen Funktionen

(Kohlenoxydderivate, freie Radikale, organische Verbindungen mit künstlichen Isotopengemischen)

11. Kapitel: Die cyclischen Verbindungen

12. Kapitel: Die Reaktionen am Kohlenstoffgerüst

(Oxydation, Reduktion, Synthese, Abbau)

II. Band:

\section{Theoretische und allgemeine organische Chemie}

1. Kapitel: Die Geschichte der organischen Chemie

2. Kapitel: Die physikalischen Hilfsmittel der organischen Chemie

3. Kapitel: Die Bindungen und Bindungssysteme der organischen Chemie

4. Kapitel: Die Reaktionen und Reaktionsmechanismen der organischen Chemie

5. Kapitel: Tautomerieprobleme

6. Kapitel: Die zwischenmolekularen Kräfte und Assoziationserscheinungen

7. Kapitel: Die Stereo- oder Raumchemie

III. Band :

\section{Sondergebiete}

1. Kapitel: Die mineralisch vorkommenden organischen Verbindungen

2. Kapitel: Die organischen Farbstoffe

3. Kapitel: Die Grundlagen der Chemie der hochmolekularen Verbindungen

4. Kapitel: Die Zucker- oder Kohlenhydrate

5. Kapitel: Die Isoprenabkömmlinge

6. Kapitel: Sonstige stickstofffreie organische Naturstoffe (Fette und verwandte Verbindungen, natürliche Phenolderivate)

7. Kapitel: Die stickstoffhaltigen organischen Naturstoffe (Eiweißstoffe, Purinderivate, Alkaloide)

8. Kapitel: Die Grundlagen der Biochemie 